Portland State University

PDXScholar

11-14-2005

\title{
Structural and Chiroptical Properties of the Two Coordination Isomers of YbDOTA-Type Complexes
}

\author{
Lorenzo Di Bari \\ Università di Pisa \\ Gennaro Pescitelli \\ Università di Pisa
}

\section{A. Dean Sherry}

University of Texas at Dallas

Mark Woods

Portland State University, mark.woods@pdx.edu

Follow this and additional works at: https://pdxscholar.library.pdx.edu/chem_fac

Part of the Inorganic Chemistry Commons

Let us know how access to this document benefits you.

\section{Citation Details}

Di Bari, L., Pescitelli, G., Sherry, A. D., \& Woods, M. (2005). Structural and chiroptical properties of the two coordination isomers of YbDOTA-type complexes. Inorganic chemistry, 44(23), 8391-8398.

This Post-Print is brought to you for free and open access. It has been accepted for inclusion in Chemistry Faculty Publications and Presentations by an authorized administrator of PDXScholar. Please contact us if we can make this document more accessible: pdxscholar@pdx.edu. 


\title{
Structural and Chiroptical Properties of the Two Coordination Isomers of YbDOTA-Type Complexes
}

\author{
Lorenzo Di Bari ${ }^{*}, \dagger$, Gennaro Pescitelli ${ }^{\dagger}$, A. Dean Sherry $\ddagger, \S$, and Mark Woods ${ }^{*}, \|, \ddagger$ \\ †Dipartimento di Chimica e Chimica Industriale, Università di Pisa, via Risorgimento 35, 56126 Pisa, \\ Italy \\ \#Department of Chemistry, University of Texas at Dallas, Richardson, Texas 75080 \\ $\S$ Rogers Magnetic Resonance Center, University of Texas Southwestern Medical Center, Dallas, \\ Texas 75235 \\ "Macrocyclics, 2110 Research Row, Suite 425, Dallas, Texas 75235
}

\begin{abstract}
Studies of the structural, physical, and chemical properties of the lanthanide(III) complexes of DOTA (1,4,7,10-tetraazacyclododecane-1,4,7,10-tetraacetic acid) and related ligands are often complicated by the presence of two coordination isomers in solution. Since these coordination isomers are in exchange and cannot be separated, many techniques offer information only on the weighted average of the two isomers. Lanthanide ion complexes formed with the ligands $S(R R R R) \mathrm{NO}_{2}$ BnDOTMA and $S(S S S S) \mathrm{NO}_{2}$ BnDOTMA preferentially adopt only one of the two common coordination isomers in solution, so the ytterbium complexes of these ligands offer a unique opportunity to study the nearinfrared circular dichroism (NIR-CD) characteristics of each coordination geometry in isolation. The spectra acquired support many of the conclusions and assumptions of previous studies and demonstrate that this spectroscopy is particularly sensitive to the distortion of the coordination polyhedron. This will have particularly relevant consequences when studying achiral YbDOTA-like systems forming labile adducts with (chiral) hosts and receptors.
\end{abstract}

\section{Introduction}

The complexes formed between lanthanide(III) ions and DOTA (Chart 1) and its derivatives have received intense scrutiny over the past two decades, largely driven by the interest in $\mathrm{Gd}^{3+}$ complexes as MRI contrast agents. Of particular interest has been the nature of the two coordination isomers that exist naturally in a solution of LnDOTA. ${ }^{1-3}$ Since the rate of water exchange is a critical parameter in contrast agent design ${ }^{2}$ and one of the two coordination isomers of LnDOTA complexes exhibits substantially faster water exchange than the other, ${ }^{4-}$ ${ }^{6}$ understanding the physical characteristics of these two coordination isomers has been an important goal. Because they are in dynamic exchange in solution, the nature of each coordination isomer historically had to be deduced from measurements performed on mixtures of the two. ${ }^{4,7}$ Inevitably, this often gives rise to results that represent a weighted average of the two coordination isomers, for example, in the optical properties of the complex. ${ }^{7,8}$

\footnotetext{
(C) 2005 American Chemical Society

*To whom correspondence should be addressed. Tel: +39 050221 9298. Fax: +39 050221 9260. E-mail: E-mail: 1db@ dcci.unipi.it (L.D.B.). Tel: +1972250 2248. Fax: +1 972250 2245. E-mail: E-mail: mark@ macrocyclics.com (M.W.).

Supporting Information Available: Assignment of the ${ }^{1} \mathrm{H}$ NMR, UV, and UV-CD spectra. This material is available free of charge via the Internet at http://pubs.acs.org.
} 
However, the recent discovery that it was possible to selectively synthesize lanthanide DOTAtype complexes that adopt just one of these coordination geometries has significantly widened the scope of investigations that can be carried out into the nature of these two coordination geometries. ${ }^{5}$ In this report, we examine the chiroptical properties in both the NIR and UV of three ytterbium complexes Yb1-3 that exhibit just one coordination isomer (Chart 1).

\section{Results and Discussion}

The marked flexibility of large macrocycles is greatly reduced when some of the atoms, and in particular heteroatoms, are involved in intra- or intermolecular interactions such as metal ion coordination. ${ }^{9}$ Thus, in complexes involving all four nitrogen atoms, cyclen adopts a [3333] conformation ${ }^{10}$ and two enantiomeric structures $(\lambda \lambda \lambda \lambda)$ and $(\delta \delta \delta \delta)$. These two forms are equally populated in cyclen owing to the 4-fold symmetry of its complexes. When reported, exchange between these two structures is typically faster than $10 \mathrm{~s}^{-1} .4,7,11,12$ Such rapid exchange precludes the physical separation of the two species yet is slow enough to observe separate NMR resonances for each species in many paramagnetic complexes.

If additional chiral centers are introduced into these complexes, the enantiomeric structures $(\lambda \lambda \lambda \lambda)$ and $(\delta \delta \delta \delta)$ are rendered diastereomeric and unequal populations of the $(\lambda \lambda \lambda \lambda)$ and $(\delta \delta \delta \delta)$ structures are possible. The presence of the $p-\mathrm{NO}_{2}$ benzyl substituent on the ring leads to an ananchomeric compound, ${ }^{13}$ in close similarity with cyclohexanes; the bulky group tends to occupy a less hindered equatorial position and makes the macrocycle inversion impossible (or at least very strongly biased in favor of one form). This means that the configuration of the chiral center on the macrocycle (the carbon atom bearing the substituent) determines the chirality of the entire cyclen ring, irrespective of chirality at the pendant arms. There is, however, a notable difference with respect to cyclohexanes; that is, the 12-membered ring in a [3333] conformation projects into a square with four carbon atoms at the corners and four on the sides (the nitrogens are also on the side), as shown in Figure 1.

Assuming that the bulky substituent occupies an equatorial position, this displaces the $(\lambda \lambda \lambda \lambda)$ $\rightleftarrows(\delta \delta \delta \delta)$ equilibrium in such a way that the $(\lambda \lambda \lambda \lambda)$ conformation is preferred if the substituent replaces a pro- $R$ hydrogen, either at the corner or on the side of cyclen. It should be noted that the two positions are not equivalent and that on cyclen itself a methyl (or benzyl) equatorial substituent is calculated to be more stable at the corner than on the side by about $3 \mathrm{~kJ} \mathrm{~mol}^{-1}$. This immediately lets us deduce that the $p$ - $\mathrm{NO}_{2}$ benzyl substituted compounds $\mathrm{Yb} \mathbf{1}, \mathrm{Yb} 2$, and $\mathrm{Yb3}$, prepared from $(S)$-benzylcyclen, would be expected to display a $(\delta \delta \delta \delta)$ conformation of the macrocycle. This stereochemical element must be combined with the orientation adopted by the pendant arms; all DOTA derivatives are characterized by a very strong cooperativity, wherein the $g^{ \pm}$(Figure 2) conformation of one acetate (or its derivative) arm is uniquely associated with the same twist as all the others. This leads to a regular square arrangement of the four oxygen atoms. The coordination polyhedron of the lanthanide ion then is constituted by two squares: one featuring $\mathrm{N}$ atoms and the other featuring $\mathrm{O}$ atoms at the corners and defining a square antiprism that is twisted either considerably or only slightly. This introduces another chiral element, associated with the $\Delta$ or $\Lambda$ configuration of the pendant arms around the $\mathrm{Ln}^{3+}$ ion. It is well-known that the two stereochemical elements outlined above combine into two enantiomeric pairs $\Delta(\delta \delta \delta \delta) / \Lambda(\lambda \lambda \lambda \lambda)$ and $\Lambda(\delta \delta \delta \delta) / \Delta(\lambda \lambda \lambda \lambda)$ in the case of LnDOTA complexes, leading to a twisted square antiprismatic (TSAP) or square antiprismatic (SAP) $\mathrm{Ln}^{3+}$ coordination, respectively. These four stereoisomers become diastereomeric upon substitution at either the macrocycle or a pendant arm.

The chirality of the methyl acetate pendant arms in LnDOTMA ${ }^{-}$complexes determines only one sense of twist in the antiprism. Because the bulky methyl group must be anti to $\mathrm{Yb}$ with respec-t to the $\mathrm{C}-\mathrm{N}$ bond, the $(R)$-methyl acetate leads to the $\Lambda$ conformation (Figure 2). ${ }^{15}$ 
Conversely, an $S$ configuration leads to a $\Delta$ conformation. In compounds $\mathrm{Yb} \mathbf{1}$ and $\mathrm{Yb} \mathbf{2}$, there is a combination of labile (conformational) chirality and inert (configurational) elements, which on the basis of the above discussion allows one to predict that $Y b 1$, with its configuration $S(R R R R)$, will be a $\Lambda(\delta \delta \delta \delta)$ SAP coordination geometry, while the inert stereochemical elements of $\mathrm{Yb} 2, S(S S S S)$, will induce a $\Delta(\delta \delta \delta \delta)$ TSAP conformation. The situation for $\mathrm{Yb} 3$ is less immediately clear, owing to its mixed configuration at the pendant arms, and this prevents total symmetry of the pendant arms. However, this situation is similar to that prevailing in a related carboxyethyl-DOTA derivative; in this case, the pendant arms of the $R R R S$ isomer were found to adopt a single conformation, $\Delta$ or $\Lambda$, and did not interchange. ${ }^{4}$ The single inverted methyl acetate is presumably forced into a syn orientation around the $\mathrm{C}-$ $\mathrm{N}$ bond with the others adopting the more favorable anti orientation.

\section{Analysis of the Paramagnetic NMR Shifts}

The presence of one benzyl substituent on cyclen breaks the symmetry of DOTMA and renders all the nuclei in the complex nonequivalent. We can immediately observe that the structures of the three spectra closely resemble those of YbDOTA and YbDOTMA (Figure 3), except that here the signals are more spread out and only cluster around the values observed for the symmetrical species. In particular, while the ${ }^{1} \mathrm{H}$ shifts for $\mathrm{Yb} 2$ and $\mathrm{Yb} 3$ are close to those of the major species of YbDOTMA, for Yb1, the major species of YbDOTA is a much better comparison.

The magnetic susceptibility is a function of the coordination number (and/or of the nature of the axial ligand $)^{16}$ and, as recently demonstrated by Mironov's calculations,,${ }^{17}$ also of the twist angle of the coordination polyhedron.

The ${ }^{1} \mathrm{H}$ and ${ }^{13} \mathrm{C}$ spectra can be partially assigned through homonuclear (COSY) and heteronuclear (HMQC) correlation spectroscopy: well-defined coupling patterns identify the ethylenic moieties and identify unambiguously the equatorial and axial protons, as well as the methyl acetates. However, the lack of $J$ connectivity across the nitrogen atoms prevents the complete assignment on the basis of correlation experiments. The short $T_{1}$ values of protons in these complexes exclude the possibility of using nuclear Overhauser enhancement spectroscopy (NOESY) to circumvent this problem. The assignments of the spectra are thus presented blockwise in the electronic Supporting Information (ESI S1). The final assignment of the NMR spectra was performed by exploiting the structural information encoded in the shifts and in the relaxation rates. Two geometries for compounds $\mathrm{Yb} 1$ and $\mathrm{Yb} 2$ were produced by means of molecular mechanics (MM) calculations, ${ }^{18}$ using the Spartan MMFF force field. ${ }^{18 \mathrm{a}}$ Restraints were added relative to the $\mathrm{Yb}-\mathrm{N}$ and $\mathrm{Yb}-\mathrm{O}$ distances, set to 256 and $227 \mathrm{pm}$, respectively, in agreement with previously calculated optimal distances. ${ }^{19}$ The conformational space was sampled through Monte Carlo calculations, which led, for both $\mathrm{Yb1}$ and $\mathrm{Yb2}$, to two strongly preferred minima. The resulting geometries (Figure 4) are characterized by a coordination polyhedron, ensuring an almost perfect $C_{4}$ symmetry, and by nearly ideal gauche conformations of the ethylene bridges; the largest deviations are found far away from the benzyl substituent and are smaller than $7^{\circ}$. Nonsymmetrical structures were found having energies more than $8 \mathrm{~kJ} \mathrm{~mol}^{-1}$ above the absolute minima. The benzyl substituent occupies the equatorial position at a corner carbon; structures with axial substituents had energies at least $4 \mathrm{~kJ} \mathrm{~mol}^{-1}$ higher. The absolute minima found for $\mathrm{Yb} 1$ and $\mathrm{Yb} 2$ are fully consistent with the ${ }^{1} \mathrm{H}$ relaxation times analysis.

The slight difference in the ${ }^{1} \mathrm{H}$ longitudinal relaxation rates, $\rho_{1}$, and in the distances, $r$, of the various nuclei from $\mathrm{Yb}$ in the $\mathrm{MM}$ structure was used to guide the assignment of the ethylenic and of the methyl acetate groups. It is well-known that the paramagnetic contribution to ${ }^{1} \mathrm{H}$ relaxation rates dominates over other terms in such small complexes, and this leads to an $r^{-6}$ dependence (eq 1). 


$$
\rho_{1}=\text { const } \times r^{-6}
$$

The situation concerning the pseudocontact shifts is a little more complicated in the present case, owing to the lack of axial symmetry. In contrast to many other DOTA-like systems, the simplified McConnel-Robertson equation cannot be used and one must resort to the full equation (eq 2), ${ }^{20}$

$$
\begin{array}{r}
\delta^{\mathrm{pc}}=-\operatorname{tr}(\tilde{\chi} \tilde{\mathbf{T}})=-\frac{1}{r^{5}}\left[\left(\chi_{\mathrm{zz}}-\frac{\chi_{\mathrm{xx}}+\chi_{\mathrm{yy}}}{2}\right)\left(3 z^{2}-r^{2}\right)+\right. \\
\left.\frac{\chi_{\mathrm{xx}}-\chi_{\mathrm{yy}}}{2}\left(3 x^{2}-3 y^{2}\right)+6 \chi_{\mathrm{xy}} \mathrm{xy}+6 \chi_{\mathrm{xz}} \mathrm{xz}+6 \chi_{\mathrm{yz}} \mathrm{yz}\right]
\end{array}
$$

where $(x, y, z)$ are the nuclear coordinates in an axes system centered at ytterbium and the various $\chi_{i j}$ terms are the Cartesian components of the magnetic susceptibility tensor. An interpretation of the spectra of $\mathrm{Yb} 1$ and $\mathrm{Yb} 2$ was achieved with the aid of the program PERSEUS. ${ }^{21,22}$ The MM structures for Yb1 and Yb2 were assumed for the input ligand geometry. These provided reasonably good fits of the $\delta^{\mathrm{pc}}$, leaving only the five independent components of the tensor $\chi$ as variables, as shown in Table 1 and Table 2 . Any attempt to further refine these structures in order to reduce the root mean square (rms) deviation would be vain, and so, these structures must be regarded as ultimate. In fact, it should be borne in mind that no separation of the contact contribution to the paramagetic shift was attempted, which introduces an uncertainty in $\delta^{\mathrm{pc}}$ as large as $4 \mathrm{ppm} .{ }^{19,20,23}$ Moreover, as outlined above, the experimental evidence of the assignment was incomplete and a permutation of the groups of spins indicated in ESI (S1) might well be possible.

It is not surprising that the resulting $\chi$ tensors for $\mathrm{Yb} 1$ and $\mathrm{Yb} 2$ are similar, differing primarily in a scale factor. The two tensors display a small asymmetry, and the main axis is perpendicular to the cyclen pseudoplane. The main principal component for Yb1 is about 5800, while for Yb2 it is 3200, in close analogy with the two forms (SAP and TSAP) of YbDOTA and YbDOTMA. ${ }^{7,15}$

As was observed for YbDOTA and YbDOTMA, ${ }^{7,11}$ the proportionality between the shifts of $\mathrm{Yb} 1$ and $\mathrm{Yb} 2 \mathrm{implies}$ that the same set of geometrical factors may fit both spectra. In the present case, however, the presence of substituents on both the cyclen ring and the pendant arms removes any ambiguity. To build a TSAP structure for Yb1, one would have to either invert the macrocycle or rotate the sidearms. Both operations can be ruled out: for the former, the benzyl group would adopt an axial position, and for the latter, the methyl group and the acetate hydrogen need to switch positions. In both cases, the magnetic environment of the nuclei would change completely and, thereby, produce different shifts. Therefore, Yb1 and Yb2 can be considered frozen analogues of the minor and major forms of YbDOTMA, respectively. It is remarkable how the small asymmetries in both the molecular structure and the magnetic susceptibility tensor are largely amplified in the pseudocontact shifts, which are scattered by up to $40 \%$ for correspondent nuclei.

The situation for $\mathrm{Yb3}$ is more complicated, in part because the configuration of the acetate in the 1-position is opposed to those in the other three positions. This methyl group has at least one profound effect on the complex, determined from the COSY spectrum. In contrast to the cases of both $\mathrm{Yb1}$ and $\mathrm{Yb2}$, the benzylic substituent was found to occupy an equatorial position on the "side" of the macrocycle rather than on the "corner". This is clearly seen from the proton coupling schemes [ESI (S1)]. The reasons for and implications of this shift in position remain unclear. From inspection of the spectrum (Figure 3), it can be observed that the resonances of this complex are scattered to a greater extent than those of Yb2. Owing to problems modeling 
this complex and fitting the nuclear coordinates to a spectrum with such a high degree of scatter, no final assignment of the NMR spectrum of this complex has been possible to date. These fitting problems may stem from an increase in the nonaxial contribution to the overall ligand field which inevitably renders fitting more difficult.

\section{Near-Infrared Circular Dichroism (NIR-CD) Spectroscopy}

With reliable models of $\mathrm{Yb} \mathbf{1}$ and $\mathrm{Yb} \mathbf{2}$ in hand, these complexes were taken forward for further study by $\mathrm{CD}$ spectroscopy. The $\mathrm{Yb}^{3+}$ ion has only two energy levels: the ${ }^{2} \mathrm{~F}_{7 / 2}$ (ground state) and ${ }^{2} \mathrm{~F}_{5 / 2}$ levels, separated by about $10750 \mathrm{~cm}^{-1}$. Because the crystal field splitting of the ${ }^{2} \mathrm{~F}_{7 / 2}$ ground state is small relative to $k T$ (at $298 \mathrm{~K}$ ), all the sublevels of this state $\left(\mathrm{M}_{\mathrm{J}}\right)$ are populated to some extent at room temperature. This means that up to 12 transitions can be observed in the spectrum of $\mathrm{Yb}^{3+}$. Acquiring the $\mathrm{CD}$ spectrum of a chiral $\mathrm{Yb}^{3+}$ complex in the near-infrared region intimately probes the coordination polyhedron of the ion and may allow important information to be gathered. Although this technique has been applied to the study of $\mathrm{Yb}^{3+}$ complexes of other octadentate cyclen based ligands, ${ }^{7,11,24-26}$ the isolation of the two coordination isomers of the single ligand $\mathrm{NO}_{2}$ BnDOTMA offers a unique opportunity to further probe the intimate nature of these two coordination geometries.

The NIR-CD spectra of $\mathrm{Yb} \mathbf{1}$ and $\mathrm{Yb} \mathbf{2}$ were recorded in aqueous solution (Figure 5). Perhaps not surprisingly, because of the difference in coordination geometry discussed previously, the two spectra are radically different, illustrating the strong sensitivity of NIR-CD to the fine structure of the coordination polyhedron. The spectrum obtained for Yb1, the SAP isomer, is much less intense than that of Yb2, the TSAP isomer. This observation has important implications for our previous results examining the NIR-CD of YbDOTMA. ${ }^{7}(R R R R)$ YbDOTMA exists as an equilibrium mixture of two coordination isomers; the $\Lambda(\lambda \lambda \lambda \lambda)$, a TSAP isomer, and the $\Lambda\left(\delta \delta \delta \delta\right.$ ), a SAP isomer. From the ${ }^{1} \mathrm{H}$ NMR spectrum (Figure 3 ), it can be seen that the TSAP isomer composes about $95 \%$ of an aqueous solution of the complex. But unlike NMR, in which the individual resonances can be identified and assigned, the results of optical spectroscopy are a weighted average of the two isomers in which two sets of transitions may overlap. Separation of the signals arising from each isomer is impossible. Moreover, a safe prediction as to the intensity of the dichroic bands cannot be made (especially on account of the limited number of NIR spectra of chiral $\mathrm{Yb}^{3+}$ reported to date), and thus, the possibility that the minor isomer contributes strongly to the overall signal could not be excluded, even to the extent that it plays an important role in the resulting spectrum, perhaps even dominating it. With these reservations in mind, the spectrum of $(R R R R)$-YbDOTMA had previously been ascribed to its major form only and the individual transitions assigned on the basis of temperature-dependent studies. ${ }^{7}$

The spectrum of (RRRR)-YbDOTMA is shown on the same axes as that of Yb2 (Figure 6). The two spectra are almost prefect mirror images of one another, a result that was predicted by the opposing conformations of the coordination geometries, $\Lambda(\lambda \lambda \lambda \lambda)$ and $\Delta(\delta \delta \delta \delta)$ for $\mathrm{Yb} 2$ and YbDOTMA, respectively. In light of this and owing to the fact that the NIR-CD spectrum of $\mathrm{Yb} 1$, a SAP isomer, is relatively weak, the assumption that the contribution of the minor form of YbDOTMA (SAP) to the NIR-CD spectrum could be neglected appears valid. The similarity of these two spectra also suggests that the carbon skeleton of the ligand does not contribute significantly to the crystal field and, thus, to the NIR-CD spectrum, even in the presence of groups characterized by a dynamic polarizability, such as the phenyl substituent in Yb2. This supports previous conclusions showing that NIR-CD is a good technique for probing the coordination polyhedron of $\mathrm{Yb}^{3+}$.

Since examples of DOTA-type $\mathrm{Yb}^{3+}$ complexes that adopt solely a SAP coordination geometry are rare, to our knowledge, no other NIR-CD spectra of such tetraacetate appended complexes 
are known. The tetraamide derivatives of DOTA that bear a bulky amide substituent are wellknown to preferentially adopt SAP coordination geometries. ${ }^{24,26,27}$

The chiral tetraamide complex (RRRR)-YbDOTAMPh has been extensively studied by NIRCD spectroscopy and only adopts a SAP coordination geometry in solution. ${ }^{24}$ The NIR-CD spectrum of $\mathrm{Yb1}$ is shown with that of $(R R R R)$ - $\mathrm{YbDOTAMPh} \bullet \mathrm{H}_{2} \mathrm{O}$ (Figure 6). There are broad similarities between the two spectra; in each spectrum four main NIR Cotton effects can be observed. It is notable that the wavelength at which these CD bands are observed for Yb1 shifts to gradually longer and longer wavelengths. The result is that the spectrum of Yb1 spans a field some $20-30 \%$ larger than that of the tetraamide complex. This shifting is presumably the result of changes to the ligand field induced by a change from amide to acetate donors. These changes in ligand field affect the splitting of the two energy levels ${ }^{2} \mathrm{~F}_{7 / 2}$ and ${ }^{2} \mathrm{~F}_{5 / 2}$, resulting in different sublevels which are reflected in a shift of the $\mathrm{CD}$ bands with respect to their center of gravity. Similar effects have been observed in other $\mathrm{Yb}^{3+}$ complexes as the electronic distribution around the metal ion is changed. ${ }^{22}$

The spectrum of $\mathrm{Yb} 1$ consists of three main broad CD bands at 944, 968, and $999 \mathrm{~nm}$, and these correlate well with those at 944, 965, and $989 \mathrm{~nm}$ of $\mathrm{YbDOTAMPh} \cdot \mathrm{H}_{2} \mathrm{O}$. The order of the signs, $-/+/-$, is the same in both spectra, in agreement with the configuration of both complexess $-\Lambda(\delta \delta \delta \delta)$. It can reasonably be concluded that these bands are diagnostic of a SAP coordination geometry. In addition to these three bands, a fourth, much sharper, band is observed at $982 \mathrm{~nm}$ in the spectrum of $\mathrm{Yb1}$ and at $977 \mathrm{~nm}$ in the spectrum of

$\mathrm{YbDOTAMPh} \cdot \mathrm{H}_{2} \mathrm{O}$. Curiously, the sign of this band, although negative in the spectrum of $\mathrm{Yb1}$, is positive in the spectrum of YbDOTAMPh $\mathrm{H}_{2} \mathrm{O}$. The work of Dickins and coworkers ${ }^{24}$ has shown that in the case of YbDOTAMPh both the magnitude and sign of this band are highly sensitive to the nature of the axial ligand of the complex. However, $\mathrm{Yb} \mathbf{1}$ and $\mathrm{YbDOTAMPh} \cdot \mathrm{H}_{2} \mathrm{O}$ both possess the same axial ligand, water. Only when the axial water ligand was replaced by a stronger field ligand, such as hexamethylphosphoramide (HMPA), did the authors observe this band becoming negative in the spectrum of YbDOTAMPh (Figure 6). A small shift in wavelength, from 977 to $975 \mathrm{~nm}$, accompanies this sign change. Replacing the axial ligand of YbDOTAMPh with a more strongly coordinating ligand, such as HMPA, was also found to reduce the lanthanide induced shift (LIS) observed in the NMR spectrum of the complex. ${ }^{24}$

The LIS in NMR experiments has been related to the crystal field parameters $\mathrm{B}_{2}{ }^{0}$ and $\mathrm{B}_{2}{ }^{2}$ that determine the magnetic anisotropy, $D$, in Bleaney's theory. ${ }^{28,29}$ For several isostructural series of complexes, this relationship has been proven correct by comparing the values of $D$ through the lanthanides series ${ }^{30,31}$ or by relating NMR and optical spectra. ${ }^{24,32}$ In addition to a correlation between $\mathrm{B}_{2}{ }^{0}$ measured in the emission spectrum of europium with LIS, the intensity of the CD band centered around $976 \mathrm{~nm}$ in the spectrum of YbDOTAMPh was found to correlate moderately well with the LIS in the NMR spectra, leading to speculation that the $\mathrm{B}_{2}{ }^{0}$ coefficient manifests itself in both of these parameters. ${ }^{24}$ Despite these regularities, it should be observed that the situation is actually much more complicated, even in these seemingly simple axially symmetric systems. ${ }^{17}$ The complexes Yb1 and Yb2 have axially symmetric coordination polyhedra, and it has already been shown that their asymmetric carbon skeletons do not play a significant role in the ligand field. From the NMR spectrum presented in Figure 3, the shifts of the axial protons in Yb1, i.e., those shifted furthest downfield (between 160 and $140 \mathrm{ppm}$ ), are considerably larger than those of YbDOTAMPh•HPMA (around 50 ppm). ${ }^{24}$ It can be concluded, therefore, that the situation prevailing in Yb1 and, presumably, all tetraacetate complexes adopting a SAP coordination geometry is more complicated than a simple extrapolation of Parker's conjecture, ${ }^{24}$ relating the NIR-CD and LIS through $\mathrm{B}_{2}{ }^{0}$, allows. Indeed, according to the accepted theories of optical activity in lanthanide complexes, 33 all nonvanishing crystal field parameters are expected to play a role in determining positions 
and intensities of the Cotton effects in the NIR-CD spectra of $\mathrm{Yb}^{3+}$ complexes. Moreover, Mironov et al. have demonstrated that the origin of magnetic anisotropy is more complex than the expressions in Bleaney's theory. ${ }^{17}$ Only to a first approximation, the difference in twist angle between the TSAP and SAP isomers should not affect $\mathrm{B}_{2}{ }^{0}$ at all, and thus, Bleaney's theory ${ }^{28,29}$ would predict identical $D$ values for both coordination geometries. In contrast, thorough calculations, undertaken by Binnemans and co-workers, ${ }^{17}$ on model coordination polyhedra and with unity charges show that for $\mathrm{Yb}^{3+} D$ is strongly sensitive to coordination geometry. Inspection of the reported curves ${ }^{17}$ shows that an 8-coordinate TSAP $\mathrm{Yb}^{3+}$ ion should be characterized by a $D$ value of about $55 \%$ of the value of a 9-coordinate $\mathrm{SAP} \mathrm{Yb}^{3+}$, in remarkably good agreement with our findings for $\mathrm{Yb} \mathbf{1}$ and $\mathrm{Yb} \mathbf{2}$, as well as with previously published data. ${ }^{15,24}$

It is evident from the NMR spectra and from the increase in spectral width of the NIR-CD spectrum of $\mathrm{Yb} 1$ that substituting amides for acetates changes the ligand field of the $\mathrm{Yb}^{3+}$ ion considerably. This change appears to directly influence the power of the axial ligand to affect the $\mathrm{CD}$ band at $982 \mathrm{~nm}$. Indeed, it is entirely possible that the presence of four strongly electron donating anionic ligands around the axial binding site renders the nature of the axial ligand of little consequence to the crystal field, limiting the effect of $\mathrm{B}_{2}{ }^{0}$ on the overall ligand field.

Ultimately, this means that the factors that govern the intensity of the CD band at $982 \mathrm{~nm}$ are far more complex in this system than they appear to be in corresponding tetraamide complexes. Thus, a straightforward extension of the correlation between the NMR data and the intensity of this CD band, as proposed by Parker on tetraamides, ${ }^{24}$ is prevented by the more complex interaction of axial and equatorial ligands in the $\mathrm{Yb} 1$ and $\mathrm{Yb} 2$ systems.

\section{UV-CD Spectroscopy}

The presence of various chromophoric groups, such as the aromatic rings in $\mathrm{Yb} \mathbf{1}$ and $\mathrm{Yb2}$, provides an opportunity for a chiroptical analysis in the UV region, as well. The most prominent band found in the absorption spectra with maximum at $285 \mathrm{~nm}, \epsilon \approx 9000-10000 \mathrm{M}^{-1} \mathrm{~cm}^{-1}$, is due to a $\pi-\pi^{*}$ transition (band ${ }^{1} \mathrm{La}$ or $\mathrm{K}$ ) of the $p$-nitrobenzyl chromophore. ${ }^{34} \mathrm{It}$ is noteworthy that the corresponding $\mathrm{CD}$ band is negative with comparable amplitude for both compounds Yb1 and Yb2 (ESI, Figure S2). Given the high sensitivity of CD spectroscopy to the absolute conformation, in particular for benzenoid transitions ${ }^{1} \mathrm{~L}_{\mathrm{a}}$ and ${ }^{1} \mathrm{~L}_{\mathrm{b}}, 35 \mathrm{CD}$ spectra demonstrate that the chirality sensed by the two aromatic rings is similar for the two compounds and is only determined by the absolute configuration at the chiral carbon on the cycle. This further supports MM- and NMR-derived structures (Figure 4), where the aromatic rings lie in almost equivalent positions with respect to the DOTMA moiety. Below $230 \mathrm{~nm}$, the UV-CD spectra result from the superimposition of various contributions from the aromatic and carboxylate ${ }^{36}$ chromophores and are, therefore, less easily interpreted.

\section{Conclusions}

As predicted, the conformation of the macrocycle substituted with a nitrobenzyl substituent in place of a pro- $S$ hydrogen is effectively frozen into a $(\delta \delta \delta \delta)$ conformation. It was also found that, in general, it is energetically most favorable for the benzylic substitutent to occupy the equatorial position on the corner rather than the side of the macrocycle. In the cases where the configuration of the chiral carbon on each pendant arm is the same, i.e., $\mathrm{Yb} \mathbf{1}$ and $\mathrm{Yb} 2$, the orientation of the twist of the pendant arms is determined by the configuration of these chiral centers. The pendant arms adopt orientations that render the methyl group anti to the metal ion. When the NMR spectra of $\mathrm{Yb} 1$ and $\mathrm{Yb} 2$ were compared to the modeled structures of these complexes, it could be determined unambiguously that $\mathrm{Yb} \mathbf{1}$ adopts a SAP geometry $(\Lambda$ $(\delta \delta \delta \delta))$ and $\mathrm{Yb} 2$ a TSAP geometry $(\Delta(\delta \delta \delta \delta))$. A complete solution of $\mathrm{Yb} 3$, which has one inverted chiral center at the pendant arms, was not possible. Nonetheless, it was possible to 
tell that the benzylic substituent shifted its position to the less energetically favorable side position.

The two diastereoisomeric complexes Yb1 and Yb2 exhibit very different NIR-CD spectra. So different are the two spectra that chiroptical spectroscopy allows immediate discrimination between the two coordination geometries SAP and TSAP. This highlights the acute sensitivity of this technique to the coordination polyhedron of the $\mathrm{Yb}^{3+}$ ion. This suggests that, ultimately, information regarding the ligand field that determines the position and rotational strength of the electronic transitions may be derived from this technique.

\section{Experimental Section}

\section{General Remarks}

${ }^{1} \mathrm{H}$ NMR spectra were recorded on JEOL Eclipse 270, Varian Inova 500, and Varian Inova 600 spectrometers operating at 270,500, and $600 \mathrm{MHz}$, respectively. Two-dimensional NMR spectra were recorded at $600 \mathrm{MHz}$. NIR-CD spectra were recorded at room temperature on a Jasco J200D spectropolarimeter operating between 750 and $1350 \mathrm{~nm}$, modified by a tandem detector $\mathrm{Si} / \mathrm{InGaAs}$ with a dual photomultiplier amplifier, and using a "semimicro" square cell with an optical path of $1 \mathrm{~cm}$. UV absorption and UV-CD spectra were recorded on a PerkinElmer Lambda 19 and on a JASCO J715 spectropolarimeter, respectively. High-performance liquid chromatography (HPLC) purifications were performed on a Water $\delta$-Prep HPLC system using a Phenomenex Luna C-18 reversed-phase $(50 \mathrm{~mm} \times 250 \mathrm{~mm})$ column. The solvent system eluted with water $(0.037 \% \mathrm{HCl})$ for $5 \mathrm{~min}$ and then with a linear gradient to $80 \% \mathrm{MeCN}$ and $20 \%$ water $(0.037 \% \mathrm{HCl})$ after $40 \mathrm{~min}$, at a flow rate of $50 \mathrm{~mL} \mathrm{~min}^{-1}$.

The complexes $\mathrm{Yb} \mathbf{1}$ and $\mathrm{Yb} \mathbf{2}$ were synthesized according to the procedures previously published for the corresponding europium and gadolinium complexes. ${ }^{5} \mathrm{Yb} 3$ was isolated as a byproduct from the synthesis of Yb1. The corresponding $S(S R R R)$ complex was also isolated from the synthesis of $\mathrm{Yb} 2$ but in low yield, and insufficient amounts of this complex were obtained to allow study of this complex. All the complexes were isolated by preparative HPLC.

\section{(1S,4S,7S,10S)- $\alpha, \alpha^{\prime}, \alpha^{\prime \prime}, \alpha^{\prime \prime \prime}-$ Tetramethyl-[(S)-2-(nitrobenzyl)]-1,4,7,10- tetraazacyclododecane-1,4,7,10-tetraacetate Ytterbium-(III) Complex (HYb1)}

HPLC $R_{\mathrm{T}}=28.18 \mathrm{~min} ;{ }^{1} \mathrm{H}$ NMR $\left(600 \mathrm{MHz}, \mathrm{D}_{2} \mathrm{O}\right) \delta=183.5\left(1 \mathrm{H}, \mathrm{H}_{\mathrm{ax}}\right), 178.7\left(1 \mathrm{H}, \mathrm{H}_{\mathrm{ax}}\right), 163.9$ $\left(1 \mathrm{H}, \mathrm{H}_{\mathrm{ax}}\right), 145.9\left(1 \mathrm{H}, \mathrm{H}_{\mathrm{ax}}\right), 45.1(1 \mathrm{H}, \mathrm{Bn}), 44.1\left(1 \mathrm{H}, \mathrm{H}_{\mathrm{eq}}\right), 37.3\left(1 \mathrm{H}, \mathrm{H}_{\mathrm{eq}}\right), 29.9\left(1 \mathrm{H}, \mathrm{H}_{\mathrm{eq}}\right), 27.3$ $\left(1 \mathrm{H}, \mathrm{H}_{\mathrm{eq}}\right), 14.8\left(1 \mathrm{H}, \mathrm{H}_{\mathrm{eq}}\right), 13.6\left(1 \mathrm{H}, \mathrm{H}_{\mathrm{eq}}\right), 13.5(1 \mathrm{H}, \mathrm{Bn}), 10.7\left(1 \mathrm{H}, \mathrm{H}_{\mathrm{eq}}\right), 9.5(2 \mathrm{H}, \mathrm{Ar}), 7.0$ $(2 \mathrm{H}, \mathrm{Ar}),-18.2(3 \mathrm{H}, \mathrm{Me}),-22.8(3 \mathrm{H}, \mathrm{Me}),-23.3(3 \mathrm{H}, \mathrm{Me}),-28.0(3 \mathrm{H}, \mathrm{Me}),-44.2(1 \mathrm{H}$, $\left.\mathrm{H}_{\mathrm{ax}}\right),-45.7\left(1 \mathrm{H}, \mathrm{H}_{\mathrm{ax}}\right),-68.4\left(1 \mathrm{H}, \mathrm{H}_{\mathrm{ax}}\right),-72.8\left(1 \mathrm{H}, \mathrm{H}_{\mathrm{ax}}\right),-96.6\left(1 \mathrm{H}, \mathrm{H}_{\mathrm{ac}}\right),-116.8\left(1 \mathrm{H}, \mathrm{H}_{\mathrm{ac}}\right)$, $-117.8\left(1 \mathrm{H}, \mathrm{H}_{\mathrm{ac}}\right),-119.6\left(1 \mathrm{H}, \mathrm{H}_{\mathrm{ac}}\right) ; \mathrm{m} / z$ (ESMS EI-) $765\left(100 \%,\left[\mathrm{M}^{-}\right]\right)$appropriate isotope patterns were observed.

\section{(1R,4R,7R,10R)- $\alpha, \alpha^{\prime}, \alpha^{\prime \prime}, \alpha^{\prime \prime \prime}-$ Tetramethyl-[(S)-2-(nitrobenzyl)]-1,4,7,10- tetraazacyclododecane-1,4,7,10-tetraacetate Ytterbium-(III) Complex (HYb2)}

HPLC $R_{\mathrm{T}}=27.98 \mathrm{~min} ;{ }^{1} \mathrm{H}$ NMR $\left(600 \mathrm{MHz}, \mathrm{D}_{2} \mathrm{O}\right) \delta=112.1\left(1 \mathrm{H}, \mathrm{H}_{\mathrm{ax}}\right), 101.1\left(1 \mathrm{H}, \mathrm{H}_{\mathrm{ax}}\right), 97.9$ $\left(1 \mathrm{H}, \mathrm{H}_{\mathrm{ax}}\right), 76.9\left(1 \mathrm{H}, \mathrm{H}_{\mathrm{ax}}\right), 33.3\left(1 \mathrm{H}, \mathrm{H}_{\mathrm{eq}}\right), 31.2(1 \mathrm{H}, \mathrm{Bn}), 21.1\left(1 \mathrm{H}, \mathrm{H}_{\mathrm{eq}}\right), 17.2\left(1 \mathrm{H}, \mathrm{H}_{\mathrm{eq}}\right), 16.3$ $\left(1 \mathrm{H}, \mathrm{H}_{\mathrm{eq}}\right), 13.0(1 \mathrm{H}, \mathrm{Bn}), 8.8(2 \mathrm{H}, \mathrm{Ar}), 7.4(2 \mathrm{H}, \mathrm{Ar}), 3.7\left(1 \mathrm{H}, \mathrm{H}_{\mathrm{eq}}\right),-1.1\left(1 \mathrm{H}, \mathrm{H}_{\mathrm{eq}}\right),-3.3(1 \mathrm{H}$, $\left.\mathrm{H}_{\mathrm{eq}}\right),-9.4(3 \mathrm{H}, \mathrm{Me}),-15.7(3 \mathrm{H}, \mathrm{Me}),-16.4(3 \mathrm{H}, \mathrm{Me}),-18.9(3 \mathrm{H}, \mathrm{Me}),-23.5\left(1 \mathrm{H}, \mathrm{H}_{\mathrm{ax}}\right),-25.0$ $\left(1 \mathrm{H}, \mathrm{H}_{\mathrm{ax}}\right),-45.5\left(1 \mathrm{H}, \mathrm{H}_{\mathrm{ax}}\right),-54.4\left(1 \mathrm{H}, \mathrm{H}_{\mathrm{ax}}\right),-65.5\left(1 \mathrm{H}, \mathrm{H}_{\mathrm{ac}}\right),-65.9\left(1 \mathrm{H}, \mathrm{H}_{\mathrm{ac}}\right),-79.2(1 \mathrm{H}$, $\left.\mathrm{H}_{\mathrm{ac}}\right),-79.5\left(1 \mathrm{H}, \mathrm{H}_{\mathrm{ac}}\right) ; \mathrm{m} / z$ (ESMS EI-) $765\left(100 \%,\left[\mathrm{M}^{-}\right]\right)$appropriate isotope patterns were observed. 
(1R,4S,7S,10S)- $\alpha, \alpha^{\prime}, \alpha^{\prime \prime}, \alpha^{\prime \prime \prime}-$ Tetramethyl-[(S)-2-(nitrobenzyl)]-1,4,7,10tetraazacyclododecane-1,4,7,10-tetraacetate Ytterbium-(III) Complex (HYb3)

HPLC $R_{\mathrm{T}}=29.56 \mathrm{~min} ;{ }^{1} \mathrm{H}$ NMR $\left(600 \mathrm{MHz}, \mathrm{D}_{2} \mathrm{O}\right) \delta=134.8\left(1 \mathrm{H}, \mathrm{H}_{\mathrm{ax}}\right), 107.6\left(1 \mathrm{H}, \mathrm{H}_{\mathrm{ax}}\right), 88.2$ $\left(1 \mathrm{H}, \mathrm{H}_{\mathrm{ax}}\right), 81.4\left(1 \mathrm{H}, \mathrm{H}_{\mathrm{ax}}\right), 26.5\left(1 \mathrm{H}, \mathrm{H}_{\mathrm{eq}}\right), 24.8\left(1 \mathrm{H}, \mathrm{H}_{\mathrm{eq}}\right), 23.8(2 \mathrm{H}, \mathrm{Ar}), 22.3(1 \mathrm{H}, \mathrm{Bn}), 17.7$ $\left(1 \mathrm{H}, \mathrm{H}_{\mathrm{eq}}\right), 16.0(2 \mathrm{H}, \mathrm{Ar}), 9.4\left(1 \mathrm{H}, \mathrm{H}_{\mathrm{eq}}\right), 8.9(1 \mathrm{H}, \mathrm{Bn}), 5.8\left(1 \mathrm{H}, \mathrm{H}_{\mathrm{eq}}\right), 3.6\left(1 \mathrm{H}, \mathrm{H}_{\mathrm{eq}}\right),-3.3(1 \mathrm{H}$, $\left.\mathrm{H}_{\mathrm{eq}}\right),-11.4(3 \mathrm{H}, \mathrm{Me}),-15.7(3 \mathrm{H}, \mathrm{Me}),-16.4(3 \mathrm{H}, \mathrm{Me}),-19.1(3 \mathrm{H}, \mathrm{Me}),-24.2\left(1 \mathrm{H}, \mathrm{H}_{\mathrm{ax}}\right)$, $-27.3\left(1 \mathrm{H}, \mathrm{H}_{\mathrm{ax}}\right),-49.0\left(1 \mathrm{H}, \mathrm{H}_{\mathrm{ax}}\right),-54.9\left(1 \mathrm{H}, \mathrm{H}_{\mathrm{ax}}\right),-56.2\left(1 \mathrm{H}, \mathrm{H}_{\mathrm{ac}}\right),-73.4\left(1 \mathrm{H}, \mathrm{H}_{\mathrm{ac}}\right),-73.6$

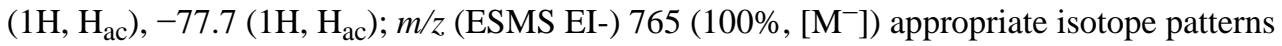
were observed.

\section{Supplementary Material}

Refer to Web version on PubMed Central for supplementary material.

\section{References}

1. Caravan P, Ellison JJ, McMurry TJ, Lauffer RB. Chem. Rev 1999;99:2293-2352. [PubMed: 11749483]

2. Aime S, Fasano M, Terreno E. Chem. Soc. Rev 1998;27:19-29.

3. Parker D, Dickins RS, Puschmann H, Crossland C, Howard JAK. Chem. Rev 2002;102:1977-2010. [PubMed: 12059260]

4. Woods M, Aime S, Botta M, Howard JAK, Moloney JM, Navet M, Parker D, Port M, Rousseaux O. J. Am. Chem. Soc 2000;122:9781-9792.

5. Woods M, Kovacs Z, Zhang S, Sherry AD. Angew. Chem., Int. Ed 2003;42:5889-5892.

6. Dunand FA, Aime S, Merbach AE. J. Am. Chem. Soc 2000;122:1506-1512.

7. Di Bari L, Pintacuda G, Salvadori P. Eur. J. Inorg. Chem 2000:75-82.

8. Beeby A, Clarkson IM, Dickins RS, Faulkner S, Parker D, Royle L, de Sousa AS, Williams JAG, Woods M. J. Chem. Soc., Perkin Trans 1999;2:493-504.

9. Meyer M, Dahaoui-Gindrey V, Lecomte C, Guilard L. Coord. Chem. Rev 1998;180:1313-1405.

10. Eliel, EEL.; Wilen, SH.; Mander, LN. Stereochemistry of Organic Compounds. New York: Wiley and Sons; 1994. p. 769

11. Di Bari L, Pintacuda G, Salvadori P. J. Am. Chem. Soc 2000;122:5557-5562.

12. Howard JAK, Kenwright AM, Moloney JM, Parker D, Woods M, Port M, Navet M, Rousseau O. Chem. Commun 1998:1381-1382.

13. In accordance with ref 10, p 1191, the term ananchomeric means "fixed in a single conformation either by geometric constraints or because of an overwhelming one-sided conformational equilibrium, as cis-4-tert-butylcyclohexanol".

14. Dale J. Top. Stereochem 1976;9:199-270.

15. Brittain HG, Desreux JF. Inorg. Chem 1984;23:4459-4466.

16. Lisowski J, Ripoli S, Di Bari L. Inorg. Chem 2004;43:1388-1394. [PubMed: 14966974]

17. Mironov VS, Galyametdinov YG, Ceulemans A, Gorller-Walrand C, Binnemans K. J. Chem. Phys 2002;116:4673-4685.

18. Spartan'02. Irvine, CA: Wavefunction, Inc.; ChemDraw 7.0.1. Cambridge, MA: CambridgeSoft Corporation; 2001.

19. Forsberg JH, Delaney RM, Zhao Q, Harakas G, Chandran R. Inorg. Chem 1995;34:3705-3715.

20. Di Bari L, Salvadori P. Coord. Chem. Rev. published online May 17 http://dx.doi.org/10.1016/j.ccr.2005.03.006.

21. Di Bari L, Pintacuda G, Ripoli S, Salvadori P. Magn. Reson. Chem 2002;40:396-405.

22. Di Bari L, Lelli M, Pintacuda G, Pescitelli G, Marchetti F, Salvadori P. J. Am. Chem. Soc 2003;125:5549-5558. [PubMed: 12720469]

23. Kemple MD, Ray BD, Lipkowitz KB, Prendergast FG, Rao BDN. J. Am. Chem. Soc 1988;110:82758287.

24. Dickins RS, Parker D, Bruce JI, Tozer DJ. J. Chem. Soc., Dalton Trans 2003:1264-1271. 
25. Di Bari L, Pintacuda G, Salvadori P, Dickins RS, Parker D. J. Am. Chem. Soc 2000;122:9257-9264.

26. Dickins RS, Howard JAK, Maupin CL, Moloney JM, Parker D, Riehl JP, Siligardi G, Williams JAG. Chem.-Eur. J 1999;5:1095-1105.

27. Woods M, Zhang S, Von Howard E, Sherry AD. Chem.-Eur. J 2003;9:4634-4640.

28. Bleaney B. J. Magn. Reson 1972;8:91-100.

29. Bleaney B, Dobson CM, Levine BA, Martin RB, Williams RJP, Xavier AV. J. Chem. Soc., Chem. Commun 1972:791-793.

30. Horrocks WD, Sipe JP. J. Am. Chem. Soc 1971;93:6800-6804.

31. Bertini I, Janik MBL, Lee YM, Luchinat C, Rosato A. J. Am. hem. Soc 2001;123:4181-4188.

32. Babushkina TA, Zolin VF, Koreneva LGJ. J. Magn. Reson 1983;52:169-181.

33. Richardson FS, Faulkner TR. J. Chem. Phys 1982;76:1595-1606.

34. Doub L, Vandenbelt JM. J. Am. Chem. Soc 1947;69:2714-2723.

35. Snatzke, G.; Kajtar, M.; Snaktzke, F. Fundamental aspects and recent developments in optical rotatory dispersion and circular dichrosim. Ciardelli, F.; Salvadori, P., editors. London: Heyden; 1973. p. 148-172.

36. Klyne, W.; Scopes, PM. Fundamental aspects and recent developments in optical rotatory dispersion and circular dichrosim. Ciardelli, F.; Salvadori, P., editors. London: Heyden; 1973. p. 126-147.

\section{Acknowledgment}

The authors thank the National Institutes of Health [EB-04285 (M.W.) and CA-84697 and RR-02584-Division of Research Resources (A.D.S.)]; the Robert A. Welch Foundation [AT-584 (A.D.S.)]; the Texas Advanced Technology Program (A.D.S.); and the Ministero dell'Istruzione, dell'Università e della Ricerca (L.D.B.) for financial support of this work. The kind help of Dr. Rachel Dickins of the University of Durham in the preparation of Figure 6 with data from ref 24 is also gratefully acknowledged. 


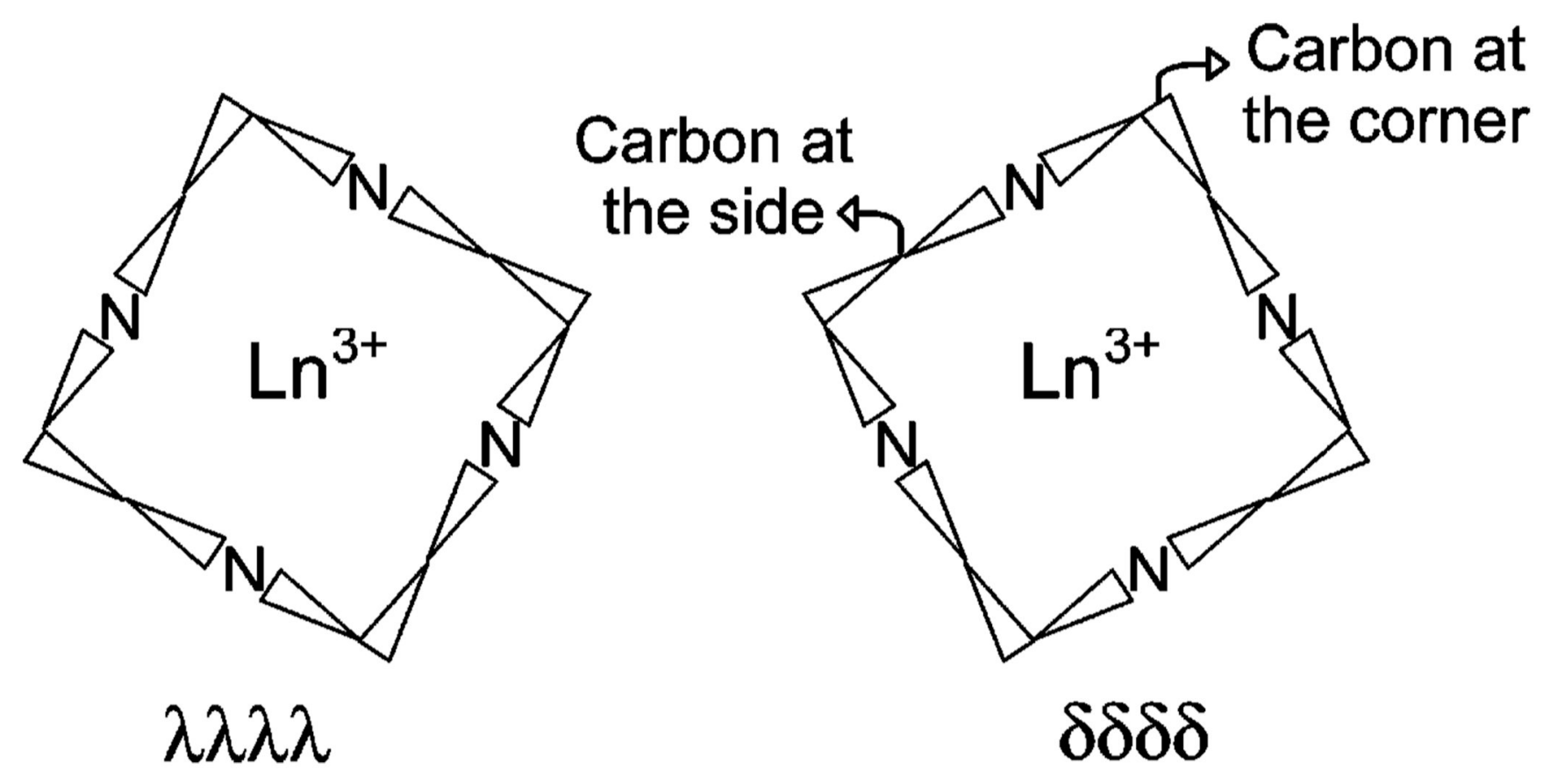

Figure 1.

Two enantiomeric conformations of cyclen shown using Dale's representations. ${ }^{10,14}$ The two kinds of nonequivalent carbon atoms (side and corner) are also indicated. 

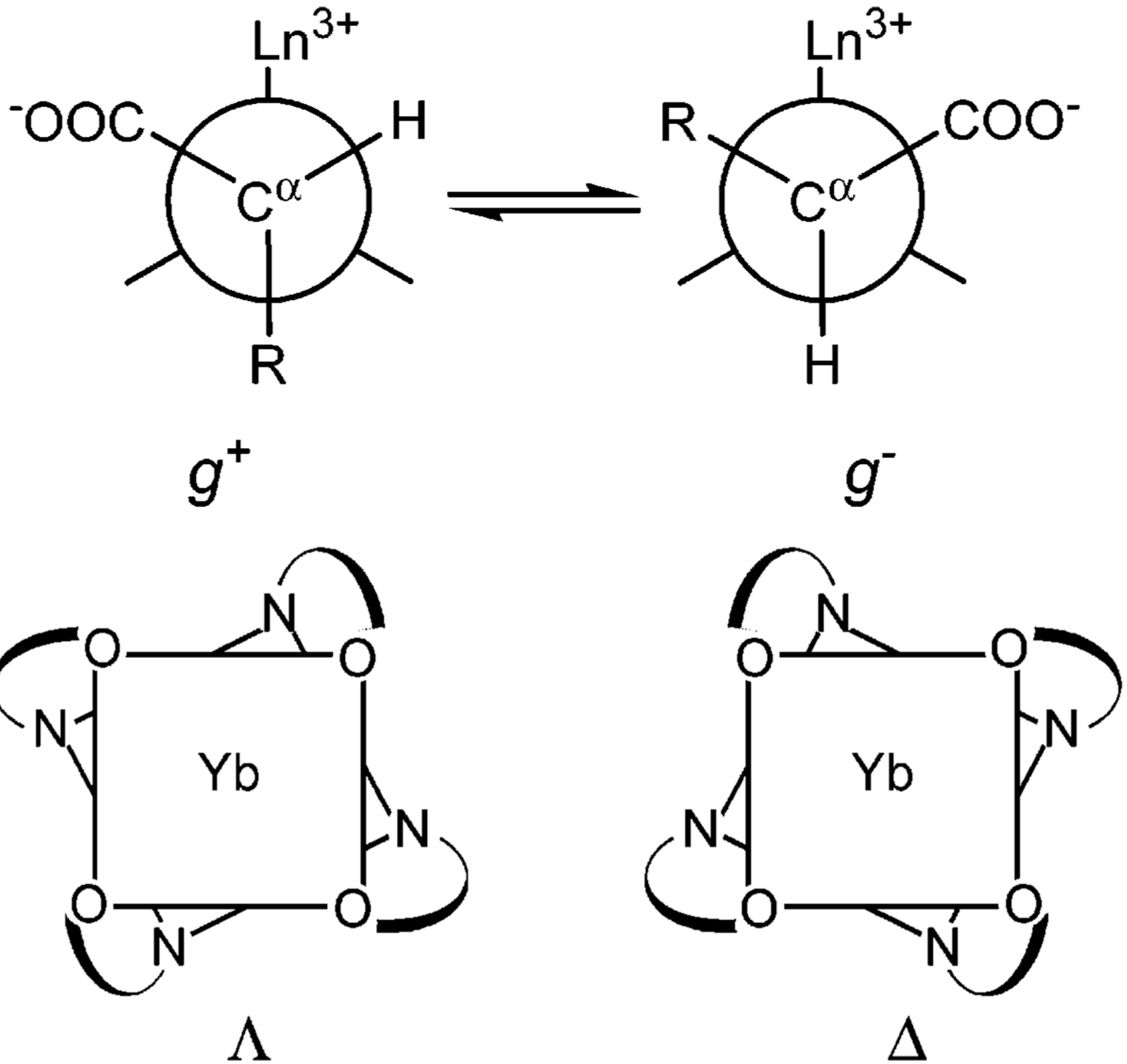

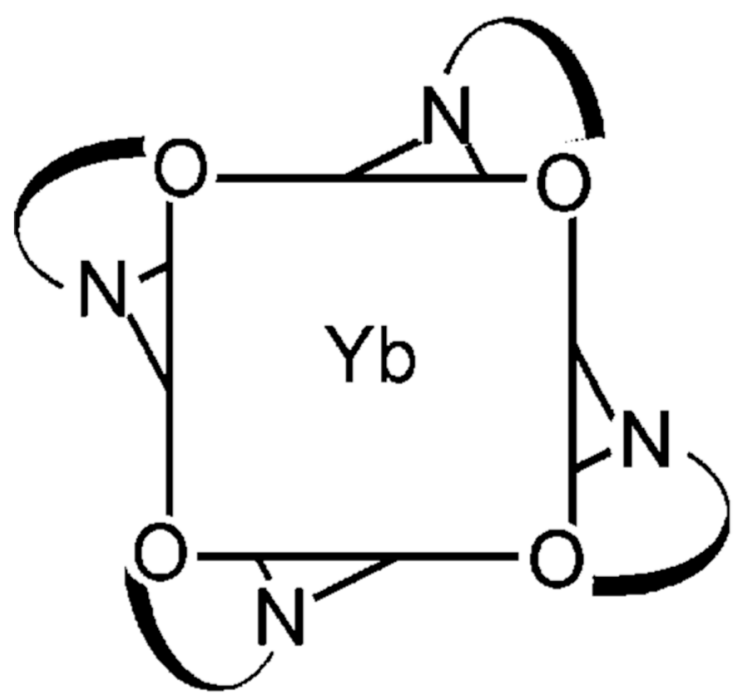

$\Lambda$

Figure 2.

Conformational analysis around the $\mathrm{C}^{\alpha}-\mathrm{N}$ bond in DOTA derivatives: $\mathrm{R}=\mathrm{H}$ in the achiral DOTA; $\mathrm{R}=\mathrm{CH}_{3}$ e.g., in $(R)$-DOTMA, where the equilibrium is pushed to the left. 


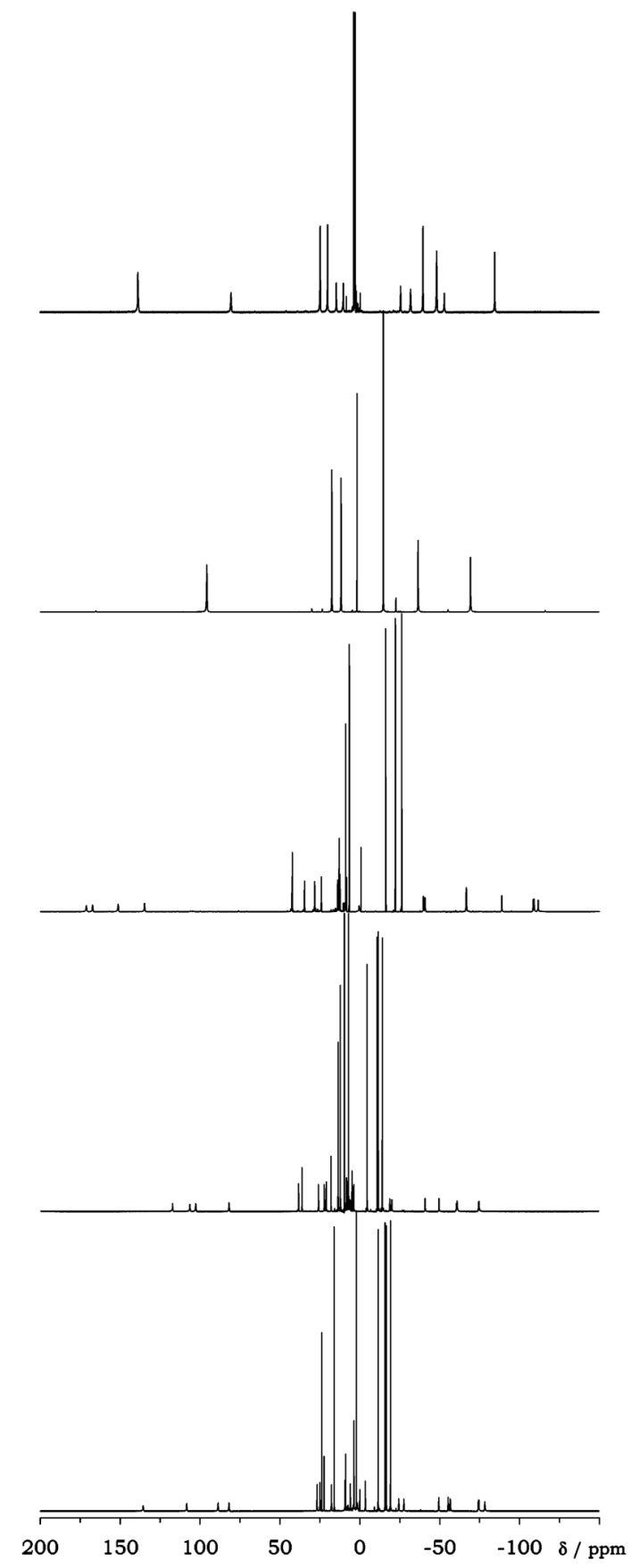

Figure 3.

${ }^{1} \mathrm{H}$ NMR spectra of (from top to bottom) YbDOTA, YbDOTMA, Yb1, Yb2, and Yb3. All spectra were recorded in $\mathrm{D}_{2} \mathrm{O}$ at $296 \mathrm{~K}$ and $500 \mathrm{MHz}$ with suppression of the residual HOD peak. 

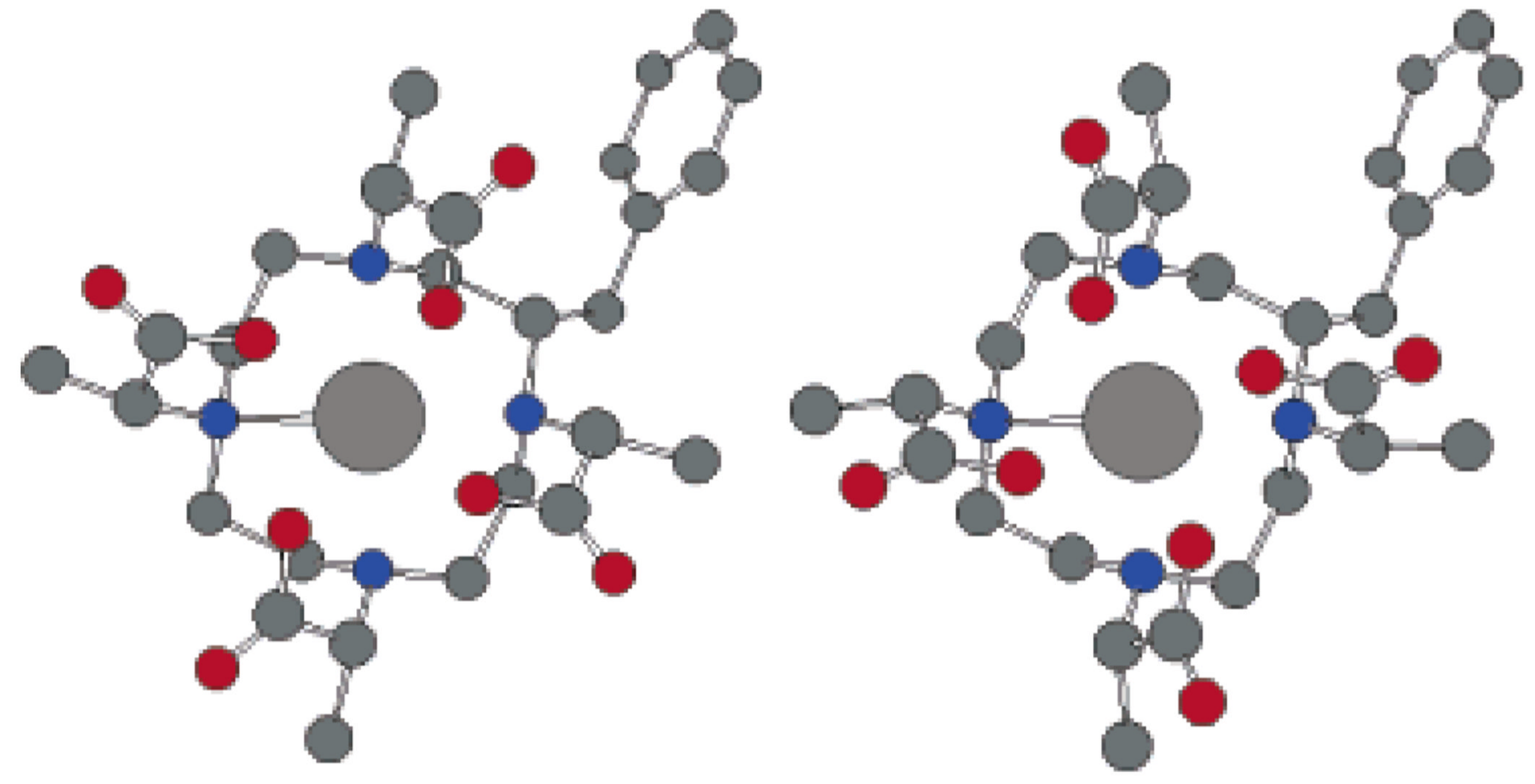

Figure 4.

MM structures for Yb1 (left) and Yb2 (right). 


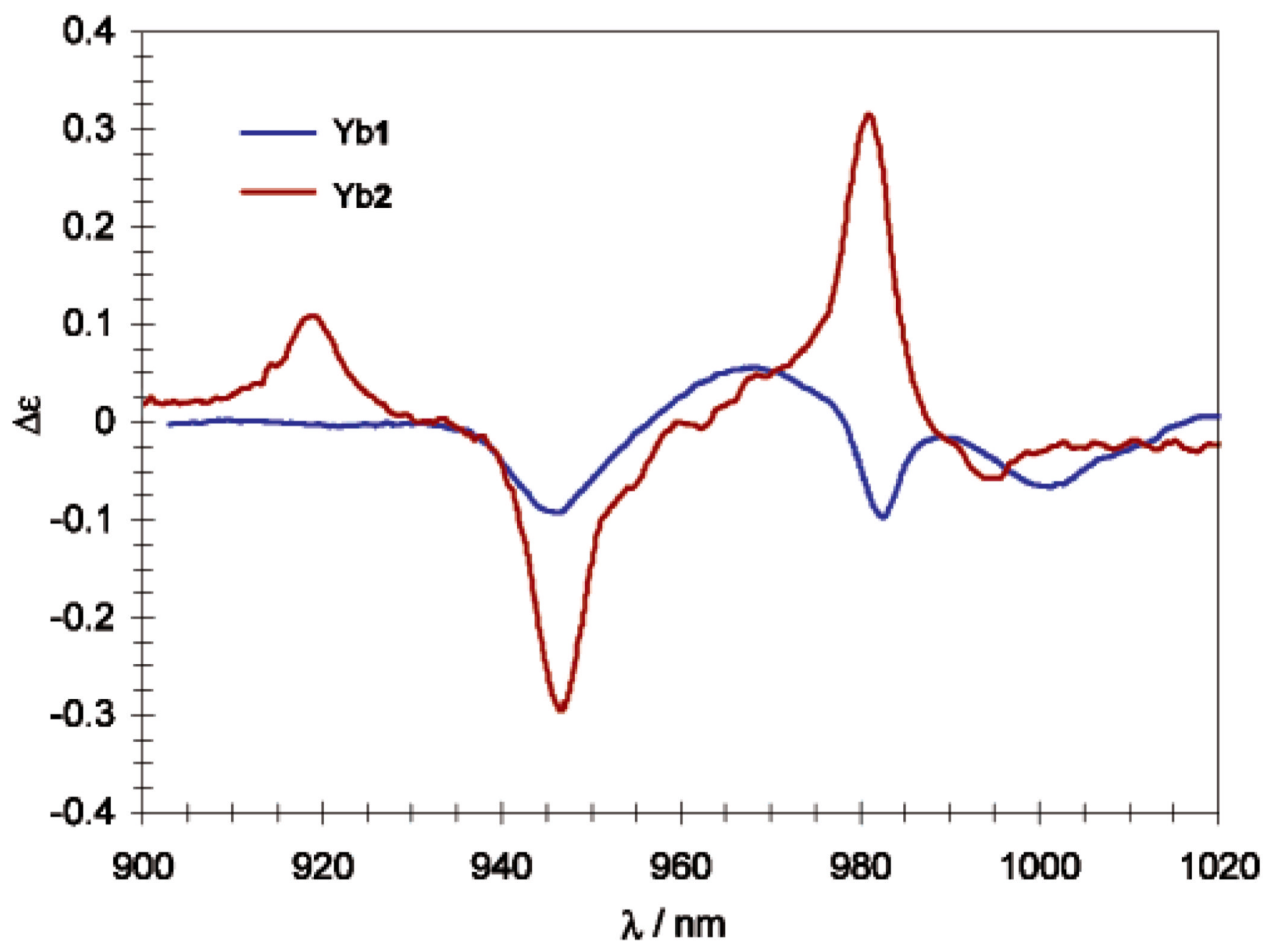

Figure 5.

Normalized NIR-CD spectra of Yb1 (blue) and Yb2 (red). 

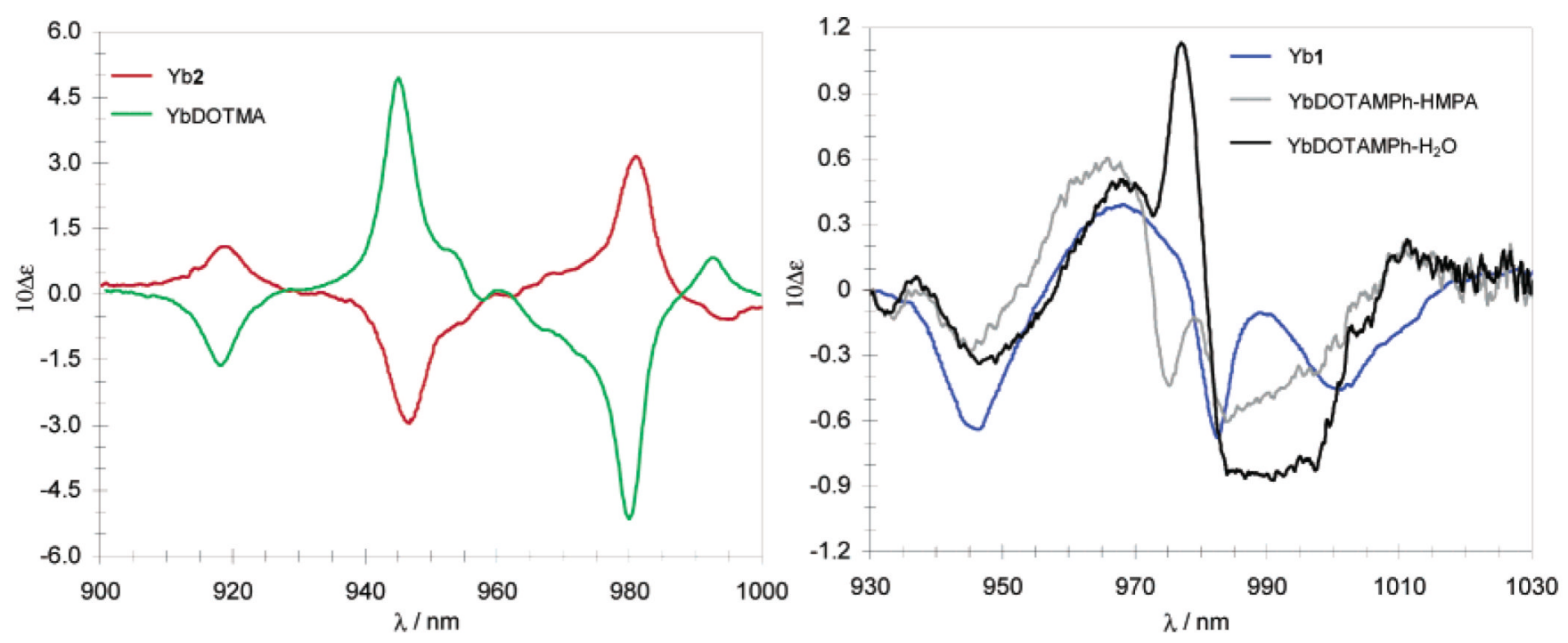

Figure 6.

Comparison NIR-CD spectra: on the left is shown a comparison of $\mathrm{Yb} 2$ (red) and (RRRR)YbDOTMA (green), ${ }^{7}$ and these complexes exist as TSAP isomers solely and primarily, respectively; on the right is shown a comparison of Yb1 (blue) and (RRRR)-YbDOTAMPh with $\mathrm{H}_{2} \mathrm{O}$ as the axial ligand (black) and HMPA as the axial ligand (gray), ${ }^{24}$ and these complexes exist solely as SAP isomers. The data for the YbDOTAMPh complexes are reproduced from ref ${ }^{24}$, with permission. 
<smiles>O=C(O)CN1CCN(CC(=O)O)CCN(CC(=O)O)CCN(CC(=O)O)CC1</smiles>

$\mathrm{H}_{4}$ DOTA

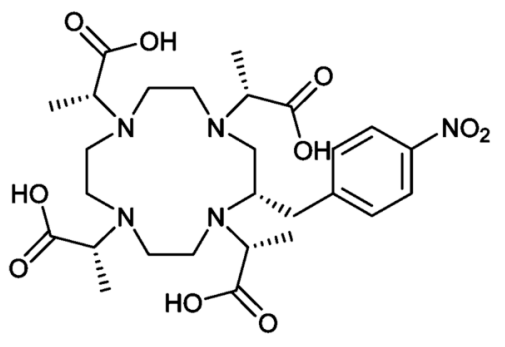

$\mathrm{H}_{4} 1$<smiles>C[C@@H](C(=O)O)N1CCN([C@@H](C)C(=O)O)CCN([C@H](C)C(=O)O)CCN([C@@H](C)C(=O)O)CC1</smiles>

$\mathrm{H}_{4}$ DOTMA

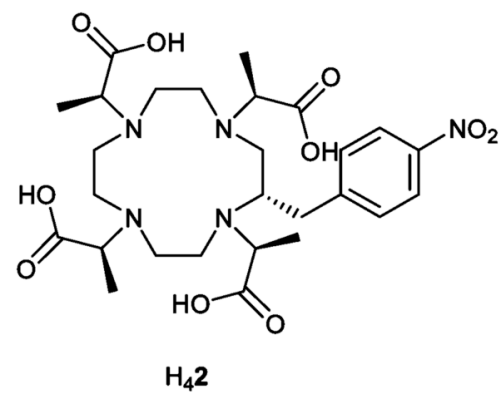<smiles>CC(NC(=O)CN1CCN(CC(=O)NC(C)c2ccccc2)CCN(CC(=O)NC(C)c2ccccc2)CCN(CC(=O)NC(C)c2ccccc2)CC1)c1ccccc1</smiles><smiles>CCN(CCN1CC(Cc2ccc([N+](=O)[O-])cc2)N(C(C)C(=O)O)CCN(C(C)C(=O)O)CCN1C(C)C(=O)O)C(C)C(=O)O</smiles>

$\mathrm{H}_{4} 3$

Chart 1. 


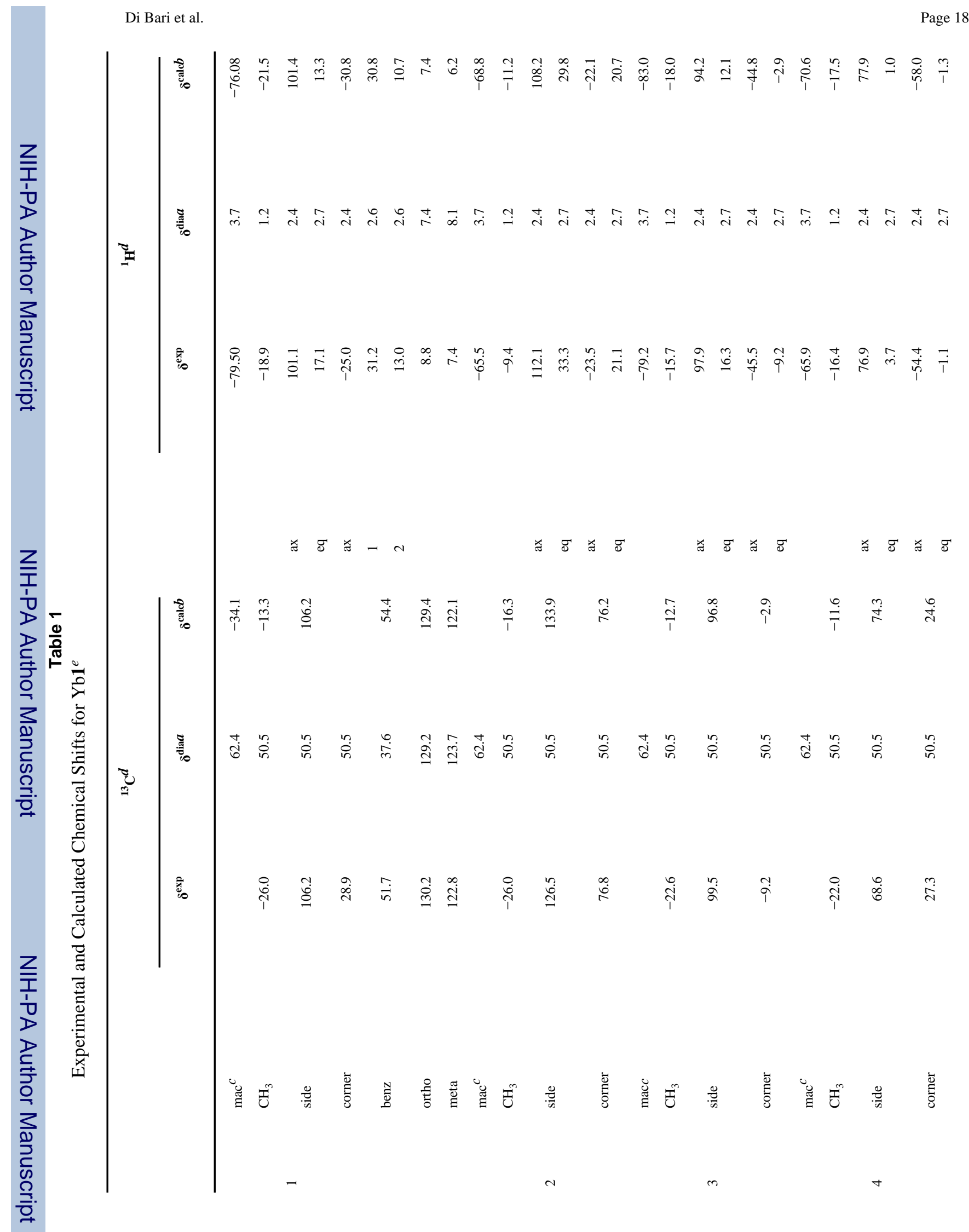

Inorg Chem. Author manuscript; available in PMC 2009 July 30. 


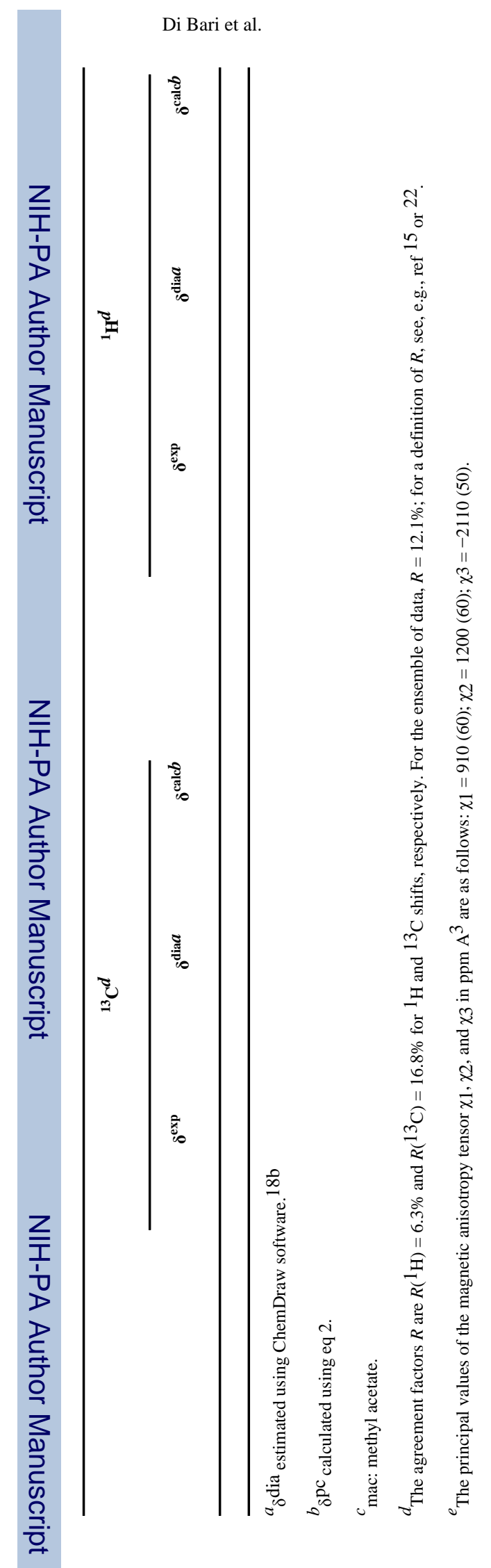

Inorg Chem. Author manuscript; available in PMC 2009 July 30. 


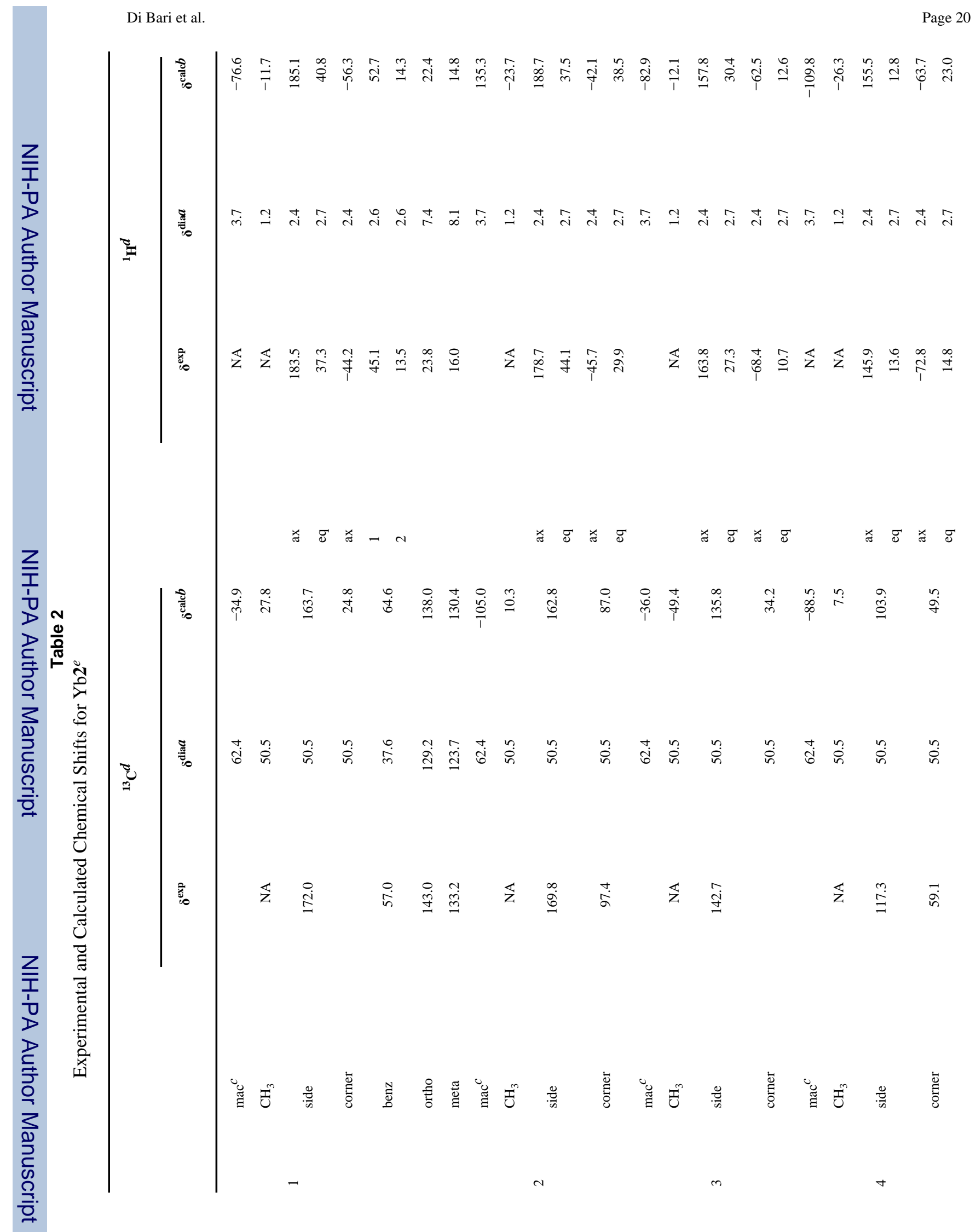

Inorg Chem. Author manuscript; available in PMC 2009 July 30. 


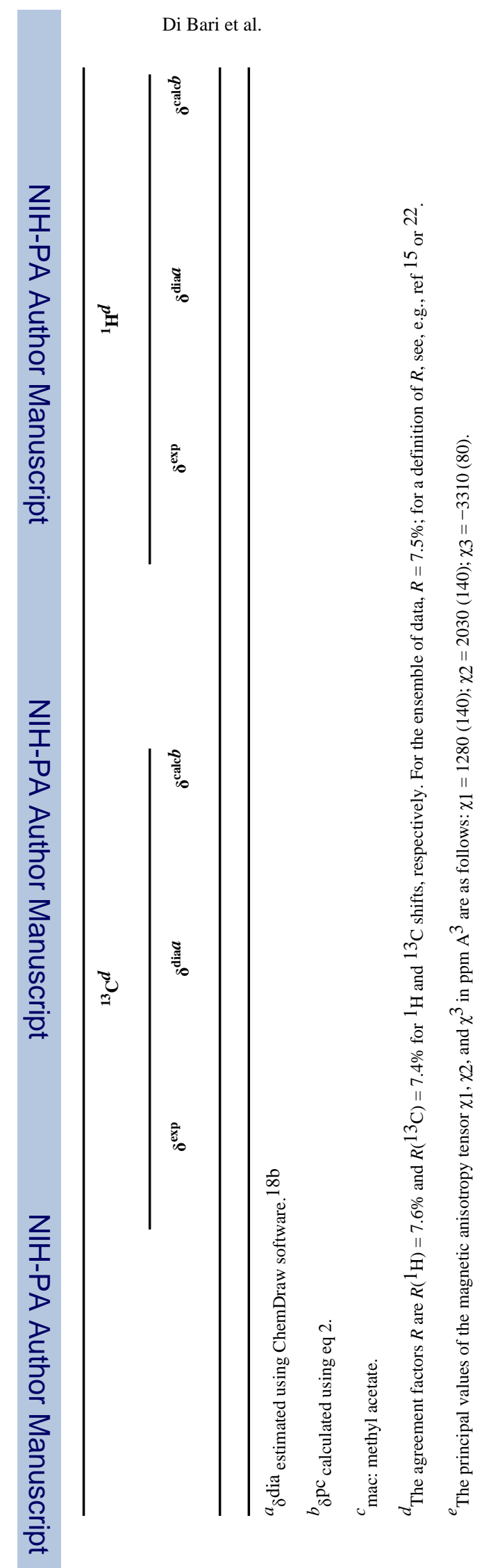

Inorg Chem. Author manuscript; available in PMC 2009 July 30. 